Document downloaded from:

http://hdl.handle.net/10251/176367

This paper must be cited as:

Verdecho Sáez, MJ.; Alarcón Valero, F.; Pérez Perales, D.; Alfaro Saiz, JJ.; Rodríguez Rodríguez, R. (2021). A methodology to select suppliers to increase sustainability within supply chains. Central European Journal of Operations Research. 29:1231-1251. https://doi.org/10.1007/s10100-019-00668-3

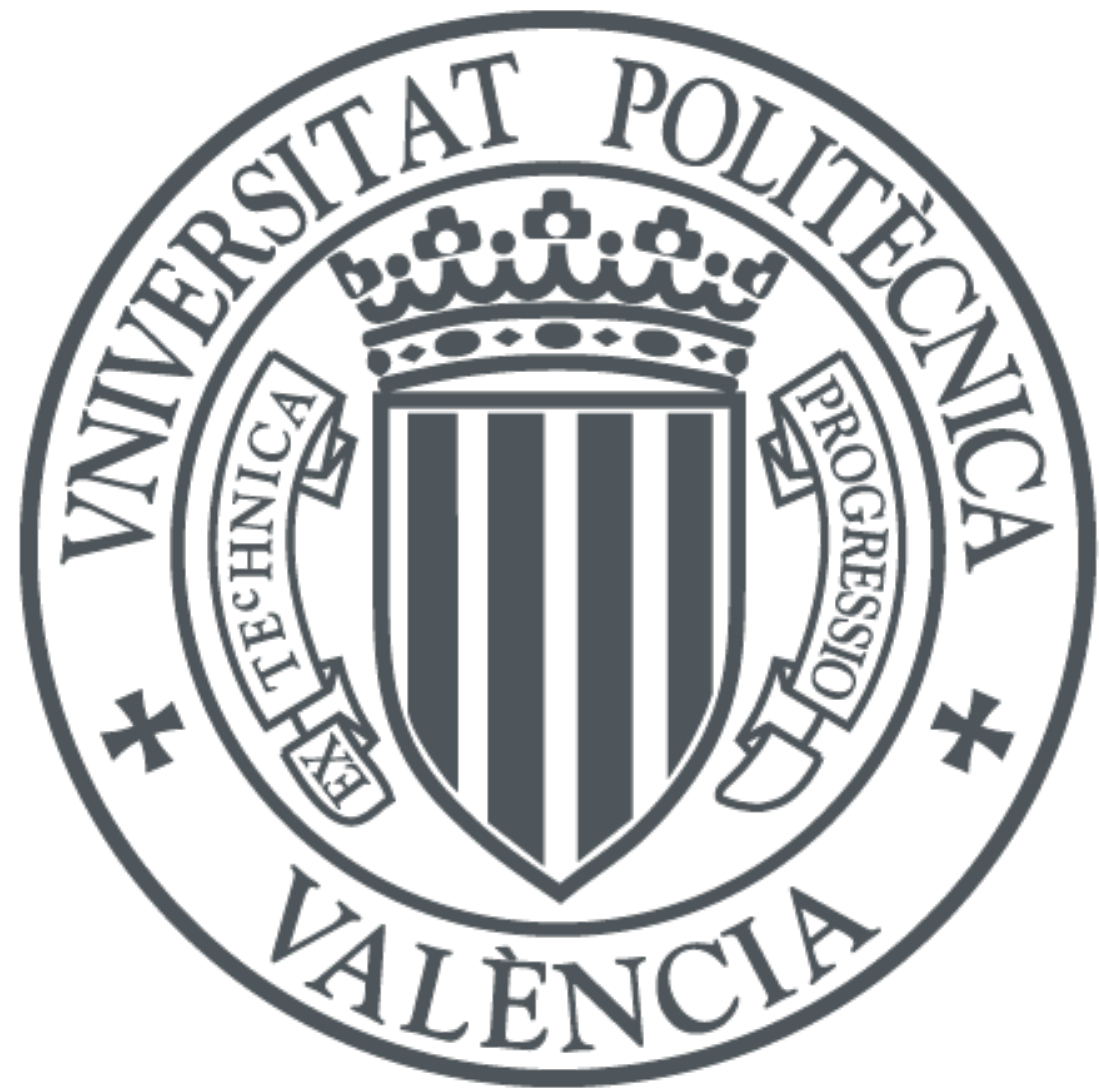

The final publication is available at

https://doi.org/10.1007/s10100-019-00668-3

Copyright Springer-Verlag

Additional Information 


\title{
A methodology to select suppliers to increase sustainability within supply chains
}

María-José Verdecho, Faustino Alarcón-Valero, David Pérez-Perales, Juan-José Alfaro-Saiz, Raúl Rodríguez-Rodríguez

Dep. Business Organisation, Research Centre on Production Management and Engineering (CIGIP), Universitat Politècnica de València, Camino de Vera s/n, Valencia, 46022, Spain

Corresponding author: María-José Verdecho, mverdecho@omp.upv.es, Telephone: +34 96387 7000 int. 76800

\begin{abstract}
Sustainability practice within supply chains remains in an early development phase. Enterprises still need tools that support the integration of sustainability strategy into their activity, and to align their sustainability strategy with the supplier selection process. This paper proposes a methodology using a multi-criteria technique to support supplier selection decisions by taking two groups of inputs that integrate sustainability performance: supply chain performance and supplier assessment criteria. With the proposed methodology, organisations will have a tool to select suppliers based on their development towards sustainability and on their alignment with the supply chain strategy towards sustainability. The methodology is applied to an agrifood supply chain to assess sustainability in the supplier selection process.
\end{abstract}

Keywords: supplier selection, sustainability, supply chain, performance, agri-food

\section{Introduction}

Managing sustainability in the supply chain (sustainable supply chain management, SSCM) can be defined as "the management of material, information and capital flows, as well as cooperation among companies along the supply chain, while taking goals from all three dimensions of sustainable development, i.e., economic, environmental and social, into account, which are derived from customer and stakeholder requirements" (Seuring and Müller 2008). From this definition, it can be inferred that if supply chains are to manage sustainability, the management supply chain has to incorporate all three dimensions, as well as customer and stakeholder needs.

The practice of supply chain sustainability remains in an early development phase. Organisations present some limitations when incorporating sustainability strategies and practices into their management, even when it is known that their operation relies on their responsibility towards stakeholders and partners in the supply chain (Dyllick and Hockerts 2002; Qorri et al. 2018). Therefore, supply chains still need tools to be developed that help to manage this complexity. It is also necessary to consider that sustainability should emerge from the supply chain's strategy. This requires that the sustainability guidance starts to formulate a robust strategy in which all the enterprises belonging to the supply chain pursue mutual objectives towards sustainability. In this vein, performance management systems (PMSs) are tools that sustain the design and implementation of organisation's strategy, as well as the establishment of mechanisms for performance monitoring. 
In the academic and business literature, several PMSs have been designed to manage interorganisational contexts. The balanced scorecard (BSC), developed by Kaplan and Norton (1992), is one of the most outstanding PMSs for organisations. The BSC was developed to manage a single enterprise, but was later extended to the management of supply chains (e.g. Brewer and Speh 2000; Bititci et al. 2005; Folan and Browne 2005; Alfaro et al. 2007). The single enterprise BSC is composed of different performance elements: perspectives, objectives, key performance indicators (KPIs), targets and action plans. A BSC comprises four perspectives: financial, customer, process, and innovation and learning. These four perspectives are defined for the enterprise's evolution in four key areas in order to gain a broader view of the enterprise's performance status. Therefore, the objectives to be fulfilled in the enterprise are defined within these four perspectives. The evolution of each objective is monitored by defining the KPIs. A target is defined for each KPI so that managers can analyse if the target is met during a pre-defined period for every KPI. Finally, action plans are defined and implemented to support objectives being met.

In an inter-organisational context, the structure of PMSs incorporates the definition of the supply chain's performance elements. In supply chains, the PMS definition is more complex, as the performance elements of both supply chains and individual enterprises should be coherent and aligned to fulfil the objectives defined for supply chains (Alfaro et al. 2007). This requirement demands a higher level of cooperation/collaboration among enterprises to define and process the performance information in the supply chain (Alfaro et al. 2010; Maestrini et al. 2017). Moreover, the structures of inter-organisational PMSs should introduce a logical path to monitor performance from a strategic to an operative (process) level (Alfaro et al. 2007). Despite these developments, the structure of the PMSs defined for supply chains still have to be adapted to manage the supply chain sustainability aligned to decision-making in the supply chain process (Nawaz and Koç 2018; Qorri et al. 2018).

One of the practices to remain competitive that has been most agreed on is to set up collaboration with suppliers (Verdecho et al. 2012; Jimenez-Jimenez et al. 2019). Enterprises need to link the inter-enterprise flows that develop within the supply chain effectively. The supplier selection process is a key process to increase profits, cut time-to-market, enhance innovation capability, etc. (Petersen et al. 2005). It has to be stated that the supplier selection problem has a multi-attribute nature that has been analysed in the literature mainly via two topics: the definition of supplier selection criteria and the usage of multi-criteria models to assess suppliers. If supply chains pursue the fulfilment of sustainability objectives, the criteria used to select suppliers should incorporate sustainability criteria to create a robust system that obtains synergy.

At this point, the enterprises that need to select suppliers and that wish to focus their efforts on increasing supply chain sustainability should incorporate two groups of inputs: supply chain performance and supplier assessment criteria. The first group, supply chain performance, refers to the overall objectives that the supply chain wishes to meet, including sustainability objectives. These objectives are better structured when using a solid PMS. Enterprises will select the suppliers that best match these objectives. The second group, supplier assessment criteria, comprises the criteria that organisations consider relevant for assessing suppliers. These criteria should include sustainability attributes to evaluate the status of suppliers in developing and implementing sustainable practices.

The aim of this paper is to develop a methodology that supports supplier selection decisions by using two groups of inputs that incorporate sustainability: supply chain performance and 
supplier assessment criteria. With this methodology, enterprises may select suppliers based on their development towards sustainability, because supplier performance criteria will not only include their sustainability practices, but their alignment with the supply chain sustainability strategy.

This work is structured as follows. Firstly, a literature review is presented that comes in three parts: sustainable supplier selection modelling approaches, sustainable supplier selection criteria and supply chain performance measurement systems. Subsequently, the methodology to select suppliers for managing sustainable supply chains is described, after which a case study is presented in an agri-food supply chain. Finally, the conclusions are presented.

\section{$2 \quad$ Literature review}

\subsection{Sustainable supplier selection modelling approaches}

The relevance of supplier selection/assessment has been recognised in the academic literature, where specific literature reviews around supplier assessment/selection models have been developed (Weber et al. 1991; Degraeve et al. 2000; De Boer et al. 2001; Ho et al. 2010; Glock et al. 2017). The literature presents different modelling approaches to address the supplier selection problem: data envelopment analysis (DEA), linear programming, multiobjective programming, fuzzy set theory, analytic hierarchy process (AHP), TOPSIS, analytic network process (ANP), etc., and their hybrid approaches. In the supplier selection problems, the evaluation of potential suppliers may involve either quantitative or qualitative criteria. The AHP method (Saaty 1980) is a multi-criteria decision analysis (MCDA) method that is useful for assessing suppliers as it incorporates both types of criteria.

Numerous applications use the AHP method for supplier selection. Ghodsypour and O'Brien (1998) develop an AHP and linear programming proposal to select suppliers and to assign optimum order quantities. Masella and Rangone (2000) develop different vendor assessment systems by focusing on the time and scope of the co-operative partnership. Akarte et al. (2001) define a multi-criteria model to assess suppliers according to four types of attribute: product development, manufacturing, quality, and cost and delivery. Huan et al. (2004) develop an AHP model for implementing a supply chain operations reference (SCOR) model to assess global supplier performance. Chan (2003) develops a supplier selection model by combining fuzzy and AHP.

In the last few years, interest in developing models that deal with sustainable supplier selection has increased (Zimmer et al. 2016). Four literature reviews (Genovese et al. 2013; Igarashi et al. 2013; Nielsen et al. 2014; Govindan et al. 2015) have addressed environmental supplier selection and one literature review (Zimmer et al. 2016) deals with sustainable supplier selection, including the social dimension. Zimmer et al. (2016) propose a classification of modelling approaches for sustainable supplier selection purposes. They consider four basic types of approach, which are used as a single model or combined: qualitative (Delphi, Ishikawa Diagram and QFD), mathematical programming (linear programming, MILP, goal programming and nonlinear programming), mathematical analytical (AHP, ANP, DEA, TOPSIS, PROMETHEE, ELECTRE, VIKOR, DEMATEL and others), and artificial intelligence (CBR, fuzzy logic, grey systems, rough set, neural networks, particle swarm, genetic algorithm and differential evolution). According to Zimmer et al. (2016), the most widespread approaches are fuzzy logic (31.1\%), AHP (18.8\%), ANP (11.4\%), DEA (8\%) and TOPSIS (7.4\%). It is worth noting that fuzzy logic is frequently combined with mathematical analytical methods, so it is not an exclusive 
category. Mathematical analytical approaches (52.9\%) are more widely used than mathematical programming ones (3.7\%).

The literature presents many models for sustainable supplier selection using mathematical analytical approaches. Noci (1997) develops an AHP model for green supplier selection. Farzad et al. (2008) propose an AHP approach to supplier evaluation and selection in a steel manufacturing company. Hutchins and Sutherland (2008) propose a model to assess the social sustainability of companies, considering the impact of their suppliers using the weighted value of individual indicators. Hsu and $\mathrm{Hu}$ (2009) apply hazardous substance management to supplier selection using ANP. Dou and Sarkis (2010) develop a model to evaluate and select various offshoring alternatives by simultaneously considering facility location factors, supplier selection metrics and sustainability factors. Shaik and Abdul-Kader (2011) propose a model for green supplier selection using MAUT. Agarwal and Vijayvargy (2012) develop a model for green supplier assessment in environmental responsive supply chains using ANP. Uysal (2012) presents an integrated model for the sustainable performance measurement of companies using DEMATEL. Azadnia et al. (2013) present an integrated approach to sustainable supplier selection employing fuzzy logic and fuzzy AHP. Falatoonitoosi et al. (2013) present a green supplier evaluation model using DEMATEL. Hsu et al. (2013) utilise DEMATEL to develop a carbon management model for supplier selection purposes. Nie (2013) develops a model for selecting green suppliers based on AHP for the biotechnology industry. Xu et al. (2013) present a model for corporate social responsibility supplier selection using AHP. Zhe et al. (2013) offer a supplier selection model with environmental factors using DEA. Dobos and Vörösmarty (2014) develop a model for green selection and evaluation using DEA. Virender and Jayant (2014) present a green supplier selection model using ANP for an agriculture-machinery industry. Theißen and Spinler (2014) put forward an ANP model for collaborative $\mathrm{CO}_{2}$ reduction in manufacturer-supplier partnerships. Shi et al. (2015) present a DEA model to select suppliers for green supply chains. Freeman and Chen (2015) present a green supplier selection model that uses AHP-entropy-TOPSIS methods. Luthra et al. (2017) develop an AHP and VIKOR model for selecting suppliers by increasing sustainability in supply chains. Awasthi et al. (2018) present a model for multi-tier sustainable global supplier selection using fuzzy AHP-VIKOR. Azimifard et al. (2018) develop a model for selecting sustainable supplier countries for Iran's steel industry using AHP and TOPSIS. Mohammed et al. (2019) put forward an integrated fuzzy AHP-fuzzy TOPSIS model to assess and rank suppliers. Xu et al. (2019) propose a sustainable supplier selection model using AHP Sort II in an interval type-2 fuzzy environment. Pishchulov et al. (2019) develop a sustainable supplier selection model by revisiting the voting AHP method.

As previously reviewed, AHP is one of the most widespread approaches used for supplier selection; in the present work, the AHP method is a suitable method as it supports the structuring and linking of different levels and types of element (BSC elements for the supply chain and supplier selection criteria) in order to select suppliers to increase the sustainability of the supply chain.

\subsection{Sustainable supplier selection criteria}

In the literature, the frameworks and models structure the criteria for sustainable supplier selection into different dimensions and levels. Organisations use various dimensions to structure criteria to select suppliers and to apply different numbers of criteria depending on their own needs. Literature reviews collect criteria structured by dimensions, but decisionmakers adapt them to their case. The nature and number of criteria used have to be relevant 
to the studied case. Bai and Sarkis (2010) present a framework with three dimensions: business and economic, environmental and social. The business and economic dimension comprises classic business supplier selection criteria such as cost, quality, time, flexibility and innovativeness, as well as organisational criteria such as culture, technology and relationships. The environmental dimension includes pollution controls, pollution prevention, the environmental management system, resource use and pollution produced. The social dimension consists of employment practices, health and safety, and the influence of local communities, contractual stakeholders and other stakeholders. However, the example the authors present offers only three criteria within each dimension considered in the model. At this point, it is worth noting that the inclusion of many criteria in models increases their complexity, and it is recommended that decision-makers prioritise the criteria to be applied, and that these are sufficiently representative of the situation. Depending on the method, it can encounter certain difficulties, such as the human capability to process information. This is why, when using AHP or ANP, comparing between seven +/- two elements at a time is recommended, as proposed by Saaty and Ozdemir (2003), referring to Miller (1956).

Ageron et al. (2012) develop an empirical study and include the following as criteria: price, quality, reliability (dependability), service rate, delivery performance, flexibility, size of suppliers' firm, supplier certifications, associated services, length of relationships, location, environmental aspects, economic dependency, application of information technology/information systems, and social responsibility. In the results obtained in their study, classic criteria like quality, price, reliability, service rate, delivery and flexibility feature in the top ranking, while environmental issues are in the middle-low ranking and social responsibility is in the low ranking. These results indicate that some traditional criteria are highly valued and that concerns about environmental issues are higher than those about social issues. Govindan et al. (2013) structure the criteria into three dimensions: economic, green and social. The economic dimension considers costs, delivery reliability, quality and technology capability. The green dimension consists of pollution production, resource use, eco-design and the environmental management system. The social dimension integrates employment practices, health and safety, the influence of local communities and the influence of contractual stakeholders. Zimmer et al. (2016) structure the criteria into three dimensions in their literature review: economic, environmental and social issues. The economic dimension comprises management and organisation, financial performance, capabilities and external perception. The environmental dimension includes environmental practices and environmental performance. The social dimension includes internal social practices, social performance and external social practices. Awasthi et al. (2018) augment the criteria with another category (global risks), as their model aims for sustainable global supplier selection. It also considers the quality of relationships as an independent criterion. The authors consider five dimensions: economics, quality of relationships, and environmental, social and global risks. In the economic dimension, they consider cost, quality, flexibility, speed, dependability and innovativeness as criteria. The quality of relationships criteria are trust, effectiveness of communication and EDI. Environmental criteria are materials, energy, water, biodiversity, emissions, effluents and waste, and the supplier environmental selection procedure. Social criteria are labour practices and decent work, human rights, society, product responsibility and the supplier social selection procedure. Finally, global risks include currency risks, disruption risks through political instability, disruption risks through terrorism, and cultural comparability.

As previously stated, different structures can be used to classify the dimensions and criteria for supplier selection. Some works use the triple bottom line structure (Bai and Sarkis 2010; Govindan et al. 2013; Zimmer et al. 2016,) but others use a different structure (Ageron et al. 
2012; Awasthi et al. 2018). The structure used should help to accomplish the objective of the model. In our work, we propose four dimensions (business, structure, interaction and sustainability) (see section 3), as the structure of an organisation and soft aspects (interaction criteria) are highly important in partnerships. This is line with Zaklad et al. (2004), who suggest that 50 per cent of inter-organisational performance is due to people factors, while process and technology factors represent 30 per cent and 20 per cent respectively.

\subsection{Supply chain performance measurement systems}

The literature includes different PMSs developed for supply chain management based on the BSC. Brewer and Speh (2000) propose extending the BSC internal perspective to include the objectives of information flows and partnership management. Bullinger et al. (2002) develop an integrated measurement methodology for supply network logistics that integrates the SCOR model into an adapted BSC. Bititci et al. (2005) create a structured and solid model for measuring and managing performance in extended enterprises. This approach comprises a sequence of scorecards by building a complex structure that includes both intrinsic and extrinsic inter-enterprise coordinating measures at different levels. Folan and Browne (2005) develop an extended enterprise BSC based on the repetitiveness of a structure of four perspectives (internal, suppliers, customers and extended companies) applied to each node of an extended company. Alfaro et al. (2007) design a PMS for enterprise networks using the BSC structure. Bhagwat and Sharma (2007) present a BSC for supply chains that structures the supply chain framework developed by Gunasekaran et al. (2001) in a BSC. Thakkar et al. (2009) integrate the BSC and the SCOR for SMEs into a PMS.

The development of the BSC to include environmental and social sustainability comprises different dimensions (Figge et al. 2002; Reefke and Trocchi 2013; Tseng et al. 2015; Ferreira et al. 2016; Motevali-Haghighi et al. 2016; Valenzuela and Maturana 2016; Popovic et al. 2017; Qorri et al. 2018). The objectives pursued within the environmental dimension can be grouped into objectives associated with circular economy practices, i.e. the 4Rs (recycle, reuse, reduce and recover), objectives to prevent/manage pollution, and objectives to improve management of the environmental system. Common objectives related to the $4 \mathrm{Rs}$ are to reduce waste, reduce water consumption, reduce need for materials, increase recycling, increase reuse, reduce energy consumption, increase renewable energy use, etc. Objectives to prevent pollution involve reducing emissions, reducing environmental accidents and reducing the use of chemicals. Objectives to improve management of the environmental system include implementing environmental certification systems and selecting suppliers with environmental certification systems. The social dimension, according to Popovic et al. (2017), should improve the objectives in four categories: labour practices and decent work, human rights, society, and product responsibility. Labour practices and decent work comprises employment benefits and characteristics, employment practices and relations, health and safety (H\&S) practices and incidents, training, diversity and equal opportunities, employee welfare, and innovation and competitiveness. Human rights involves human rights implementation and integration, and basic human rights practice. Society includes community funding and support, community involvement, corruption in business, fair business operations and stakeholder participation. Product responsibility comprises consumer health and safety, product management and product satisfaction.

The BSC may or may not include additional perspectives to manage environmental and social sustainability (Figge et al. 2002). In our model, we propose to use the four classic perspectives of the BSC and two separate perspectives (environmental and social) for the sustainability 
objectives in order to both maintain the classic BSC structure and include sustainability, but also to cluster the objectives in a suitable manner for applying AHP. The specific BSC structure and strategic objectives used in a supply chain will depend on the supply chain's own strategy. The strategic objectives used for one supply chain may not be the most suitable for another.

\subsection{Conclusion}

Companies are concerned about the importance of partners' sustainable duty in their own evolution, and the sustainability of any organisation is impossible without incorporating SSCM practices (Ageron et al. 2012; Govindan et al. 2013). However, the literature lacks a methodology that selects suppliers and integrates sustainability performance into both supply chain performance and supplier assessment criteria. Hence, the main aim of the present work is to develop a multi-criteria methodology to help suppliers to bridge this gap. With this methodology, enterprises will have a tool for supplier assessment, while increasing the supply chain's sustainability by improving competitiveness.

\section{The methodology to select suppliers to increase sustainability within supply chains}

The methodology comprises six phases (Fig. 1). In phase 1, the BSC for supply chain sustainability measurements should be developed. If the supply chain has already developed a BSC, adapting green and social issues into it is the sole requirement. If the supply chain has no defined BSC, it is necessary to produce the whole BSC. The performance elements of the sustainability BSC are structured into six perspectives: the four classic Kaplan and Norton (1992) perspectives (financial, customer, process, and innovation and learning) and the two sustainability perspectives (social and environmental). The literature contains different structures to introduce sustainability strategic elements into a BSC (Figge et al. 2002). In our model, we wish to strategically manage environmental and social issues separately so that the analyses in the AHP model can be provided from the cluster structure. The environmental perspective may include objectives related to circular economy practices associated with the 4Rs, objectives to prevent/manage pollution, and objectives to improve management of the environmental system. Following Popovic et al. (2017), the social perspective may include objectives in four categories: labour practices and decent work, human rights, society, and product responsibility. The specific objectives that are considered in the sustainability perspectives (BSC environmental and social perspectives) will depend on the supply chain's strategy, which also applies to the other perspectives of a BSC. Each supply chain has its own strategy (top level) that needs to be operationalised using measurable objectives. The supply chain's environmental and social strategy will then be translated into specific measurable and significant objectives in the corresponding BSC perspectives. 


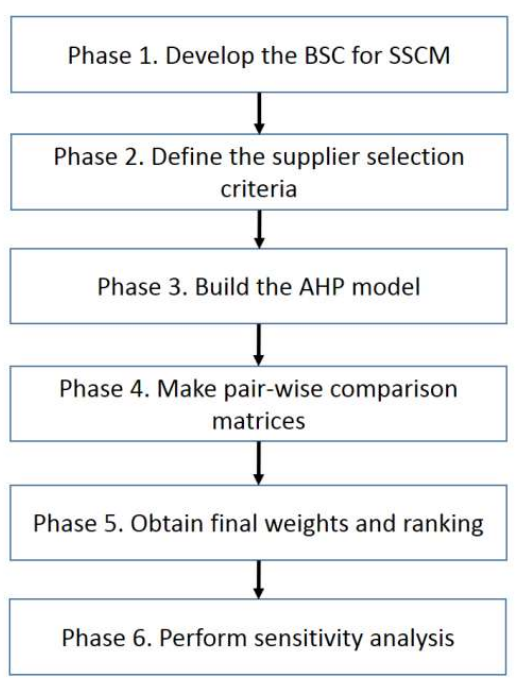

Fig. 1. Methodology

In phase 2, the supplier selection criteria are defined in four dimensions: business, structure, interaction and sustainability. Verdecho et al. (2012) present a conceptual collaboration framework to manage inter-enterprise collaborative relationships. This framework is structured into four dimensions: strategy, culture, organisational structure, and business process and information technology. Our sustainable supplier selection framework is structured into four dimensions: business, structure, interaction and sustainability. The framework of Verdecho et al. (2012) is the basis for adapting the dimensions used to select suppliers and to include sustainability criteria in the selection process. For this purpose, five adaptations are made. Firstly, we consider the definition of the BSC for the whole supply chain: the strategy dimension is mainly introduced and managed in the definition of the BSC elements (e.g. joint vision), but also in elements of the structure dimension (e.g. management support). Secondly, the business process and information technology dimension is integrated into a wider dimension called structure, which also comprises the robustness of the supplier's economic profile, internal methodologies/procedures and other structural criteria. Thirdly, the culture dimension is called interaction to design the intangible (soft factors) of the relationship. Fourthly, the business dimension comprises traditional criteria during the supplier selection process such as price, quality, delivery time, etc. Finally, the sustainability dimension is included to consider all the criteria related to environmental and social issues. The works of Bai and Sarkis (2010) and Zimmer et al. (2016) present interesting classifications of criteria for reference purposes. The specific needs, strategies and priorities of each supply chain should lead the decision on criteria selection to achieve alignment with the BSC.

In phase 3, the AHP method is used to structure the multi-criteria model. The AHP method defines the problem using a hierarchy. As Saaty (1987) suggests, "a general rule is that the hierarchy should be complex enough to capture the situation, but small and nimble enough to be sensitive to changes". The hierarchy is composed of levels linked by relationships. At the top of the hierarchy, the main objective to be fulfilled by the model is defined. The second level comprises the criteria that influence the ultimate objective being met. Afterward, several levels may be defined to structure the subcriteria and attributes. At the lowest level, different alternatives are modelled. 
Our model defines four levels (see Fig. 2): the overall objective (increase sustainability in the supply chain); the supply chain's BSC (performance elements, PE), including sustainability assessment; supplier criteria (SC); and suppliers (alternatives).

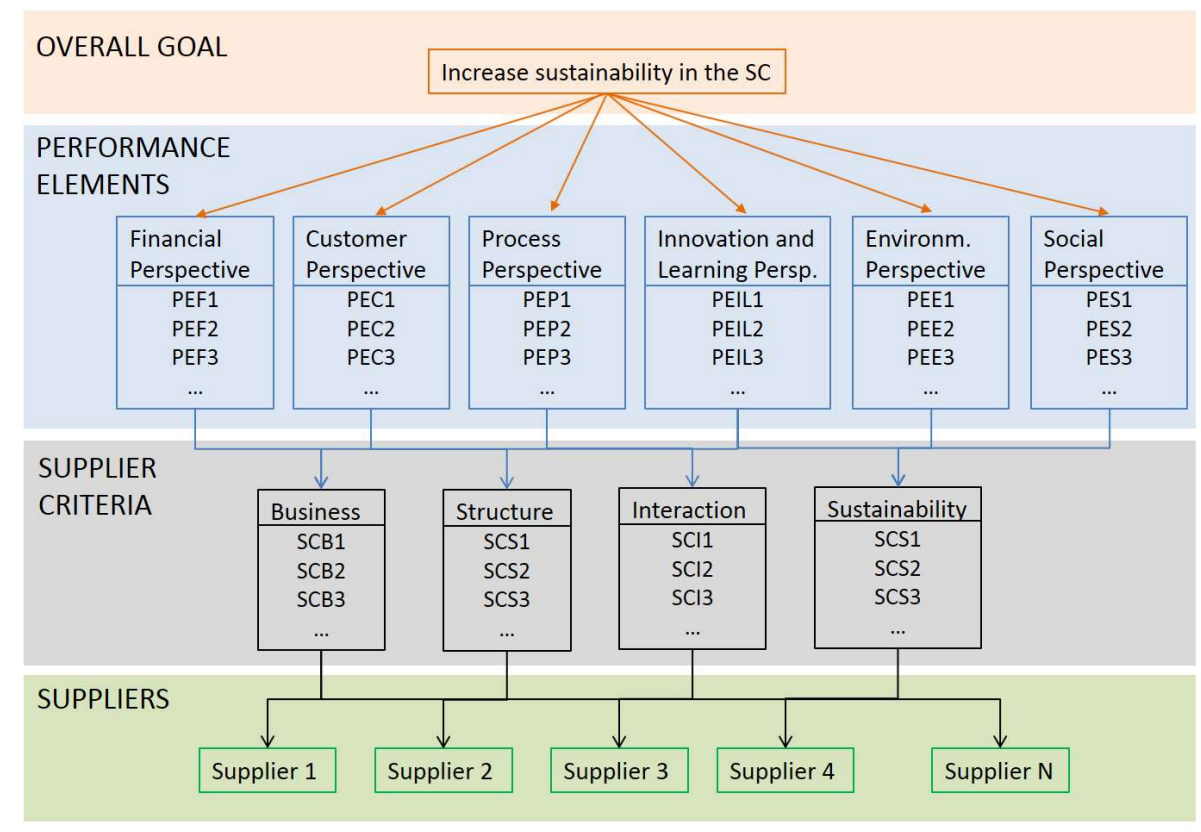

Fig. 2. The AHP multi-criteria model to select suppliers for sustainable supply chains

In phase 4, pair-wise comparison matrices are developed using the basic scale of Saaty (1980). This implies that each element at an upper level is compared with elements in the level immediately below (Saaty 2008). Then all the local priorities are computed at each level. In each pair-wise comparison matrix, it is important to check the consistency of judgements. Consistency is measured by the consistency index. Once obtained, the consistency ratio (CR) is calculated. For each matrix, CR $\leq 0.10$ assures the consistency of judgements and the model's final results are acceptable. If $C R>0.10$, then judgements have to be reviewed.

In the next phase, phase 5, the overall priorities are computed so that the final ranking of alternatives is obtained. Following Saaty (2008), the priorities obtained from the comparisons are used to weight the priorities on the level immediately below. This step is repeated for each element. Then the weighted values of each element on the level below have to be added and the overall (or global) priority obtained. Continue this process of weighting and adding until the final priorities of the alternatives at the bottom level are obtained.

Finally in the last phase, phase 6, a sensitivity analysis is performed to verify if the changes in the pair-wise comparison matrices actually affect the final ranking. What this phase does is check if the final ranking is consistent enough.

\section{$4 \quad$ Case study}

The proposal was applied to select suppliers for a supply chain from the agri-food sector using a sustainability perspective. The supply chain supplies fruits and finished products to the market and takes care of the importance of sustainability issues for its customers. Several sustainability initiatives are introduced into different processes, of which supplier selection is 
one. A committee of four decision-makers who occupied management positions (purchasing and operations) in two companies, a fruit producer and a processor, participated in the development of the case study.

Phase 1 of the proposal comprises defining the performance elements, objectives and KPIs for the six perspectives - the four BSC perspectives (financial, customer, process, and innovation and learning) and the two sustainability perspectives (environmental and social perspectives)-as the economic sustainability dimension is already introduced into the financial perspective of the BSC. Table 1 shows these elements for the six perspectives.

Table 1. Objectives and KPIs of an agri-food supply chain

\begin{tabular}{|c|c|c|}
\hline Perspectives & Objectives & KPIs \\
\hline Financial & $\begin{array}{l}\text { FO1. Cut production costs } \\
\text { FO2. Increase profitability }\end{array}$ & $\begin{array}{l}\mathrm{KPI} 1=\% \text { variation in production cost } \\
\mathrm{KPI} 2=\% \text { ROI variation } \\
\mathrm{KPI} 3=\% \text { ROA variation }\end{array}$ \\
\hline & F03. Reduce delivery cost & $\mathrm{KPI} 4=\%$ variation in delivery cost \\
\hline Customer & $\begin{array}{l}\text { CO1. Increase customer } \\
\text { satisfaction }\end{array}$ & $\begin{array}{l}\text { KPI5 = \% customer satisfied/total } \\
\text { customers } \\
\text { KPI6 = \% variation in customer } \\
\text { complaints } \\
\text { KPI7 = \% number of backorders to the } \\
\text { total number of orders } \\
\text { KPI8 = \% market share }\end{array}$ \\
\hline Process & $\begin{array}{l}\text { PO2. Increase taste } \\
\text { properties } \\
\text { PO3. Increase product } \\
\text { safety }\end{array}$ & $\begin{array}{l}\text { KPI9 = \% variation in shelf life } \\
\text { KPI10 = \% accomplishment of relative } \\
\text { humidity and temperature to comply } \\
\text { with standard regulations } \\
\text { KPI11 = \% variation in brix values } \\
\text { KPI12 = \% making laboratory checks and } \\
\text { monitoring processes according to } \\
\text { certification schemes } \\
\text { KPI13 = \% of materials with a quality } \\
\text { certification of origin }\end{array}$ \\
\hline $\begin{array}{l}\text { Innovation and } \\
\text { Learning }\end{array}$ & $\begin{array}{l}\text { IO1. Increase innovation } \\
\text { capability } \\
\text { IO2. Increase compromise }\end{array}$ & $\begin{array}{l}\text { KPI14 = \% of personnel suggestions } \\
\text { implemented } \\
\text { KPI15 = Number of policies and }\end{array}$ \\
\hline
\end{tabular}




\begin{tabular}{|c|c|c|}
\hline & of personnel & incentives developed \\
\hline \multirow[t]{9}{*}{ Environmental } & $\begin{array}{l}\text { E01. Reduce } \\
\text { environmental impacts }\end{array}$ & KPI16 = \% variation in water use \\
\hline & & KPI17= \% variation in energy use \\
\hline & & $\mathrm{KPI} 18=\%$ variation in recycling and reuse \\
\hline & EO2. Increase pollution & \\
\hline & prevention & $\begin{array}{l}\text { KPI19 = Pesticide control (quantity and } \\
\text { frequency of pesticide use according to } \\
\text { regulations). Implementation of action } \\
\text { plans (good practices) to reduce their }\end{array}$ \\
\hline & & use \\
\hline & & $\begin{array}{l}\mathrm{KPI} 20=\text { Fertiliser control (quantity and } \\
\text { frequency of fertilisers use according to } \\
\text { regulations). Implementation of action } \\
\text { plans (good practices) to reduce their }\end{array}$ \\
\hline & & use \\
\hline & & $\begin{array}{l}\text { KPI21 = Environmental certification } \\
\text { (maintain own certification and agree } \\
\text { with suppliers their commitment to } \\
\text { obtain environmental certificates such as } \\
\text { GlobalG.A.P., LEAF Marque, etc.) }\end{array}$ \\
\hline \multirow[t]{3}{*}{ Social } & \multicolumn{2}{|c|}{ SO1. Improve employmentKPI22 = Training planned per critical } \\
\hline & $\begin{array}{l}\text { SO2. Increase health \& } \\
\text { safety (H\&S) culture }\end{array}$ & $\begin{array}{l}\mathrm{KPI} 23=\text { Number of incidents and } \\
\text { accidents }\end{array}$ \\
\hline & & KPI24 = Implemented H\&S programmes \\
\hline
\end{tabular}

Phase 2 comprises defining supplier criteria into four groups: business, structure, interaction and sustainability. Table 2 shows the subcriteria for each group. Circular economy practices include criteria associated with the 4 Rs. Pollution practices include criteria to prevent/manage pollution, as well as criteria related to the environmental system management as agreed by the decision-makers.

Table 2. Supplier criteria

\begin{tabular}{ll}
\hline Criteria & Subcriteria \\
\hline Business & B1. Quality \\
& B2. Price \\
& B3. Delivery time \\
& B4. Flexibility
\end{tabular}




\begin{tabular}{ll}
\hline Structure & S1. Financial profile \\
& S2. Quality methodologies \\
& S3. Process alignment \\
\hline Interaction & I1. Coordination \\
I2. Long-term partnership \\
\hline Sustainability & SU1. Circular economy practices \\
& SU3. Employment practices \\
SU4. Health and safety practices
\end{tabular}

The AHP model is built in phase 3. Fig. 3 shows the AHP model defined in the Superdecisions ${ }^{\mathrm{TM}}$ software. The model has four levels and twelve clusters. At the top level, the main goal of this model is defined: to increase sustainability in the supply chain. This goal consists of a node in the top cluster called $1 \mathrm{Goal}$. The second level comprises six clusters of the objectives defined in Table 1, respectively corresponding to the six perspectives: 2 Financial Perspective, 3 Customer Perspective, 4 Process Perspective, 5 Innovation and Learning Perspective, 6 Environmental Perspective and 7 Social Perspective. The third level consists of the four criteria clusters defined in Table 3: 8 Business, 9 Structure, 10 Interaction and 11 Sustainability. Finally, a cluster with the alternatives (called 12 Alternatives) forms the fourth level.

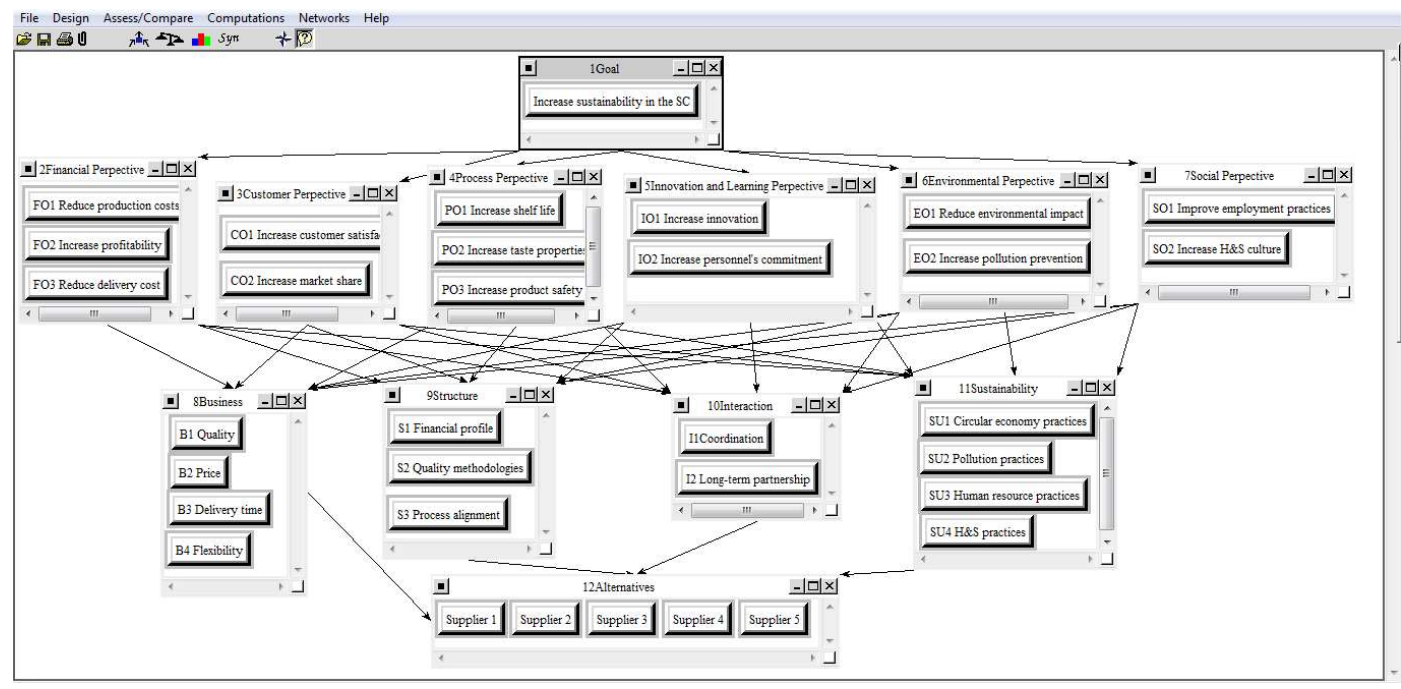

Fig. 3. AHP model in Superdecisions ${ }^{\mathrm{TM}}$

In phase 4, the decision-makers who formed the committee completed the pair-wise comparison matrices. Decision-makers met during several sessions to agree on judgements by consensus. To complete the matrices, the Saaty (1980) scale was used. First, the pair-wise comparison matrices of the different clusters of objectives in relation to the goal were completed and local priorities were obtained. Table 3 shows the pair-wise comparison matrix 
of the financial objectives in the 2 Financial Perspective cluster in relation to the goal. This table also shows the priorities and how the consistency ratio is below 0.1 .

Table 3. Pair-wise comparison matrix of the financial objectives in relation to the goal

\begin{tabular}{lcccc}
\hline & FO1 & FO2 & FO3 & Priorities \\
\hline FO1 & 1 & $1 / 5$ & 3 & 0.17818 \\
FO2 & 5 & 1 & 9 & 0.75140 \\
FO3 & $1 / 3$ & $1 / 9$ & 1 & 0.07042 \\
& & & $C R$ & 0.0279 \\
\hline
\end{tabular}

Next, the pair-wise comparison matrices of the criteria within each criteria cluster in relation to the objectives within each objective cluster were completed and local priorities were obtained. Table 4 shows the pair-wise comparison matrix of the business criteria within the 8 Business cluster in relation to the FO2 objective to increase profitability. This table also shows the priorities and the consistency ratio.

Table 4. Pair-wise comparison matrix of the business criteria in relation to objective FO2

\begin{tabular}{lccccc}
\hline & B1 & B2 & B3 & B4 & Priorities \\
\hline B1 & 1 & $1 / 3$ & 7 & 3 & 0.26587 \\
B2 & 3 & 1 & 7 & 7 & 0.58417 \\
B3 & $1 / 7$ & $1 / 7$ & 1 & $1 / 3$ & 0.04904 \\
B4 & $1 / 3$ & $1 / 7$ & 3 & 1 & 0.10093 \\
& & & $C R$ & & 0.06083 \\
\hline
\end{tabular}

In the next step, the alternatives were compared in relation to each criterion. Table 5 shows the pair-wise comparison matrix for the five suppliers in relation to the SU1 Circular economy practices criterion. This table shows the following priorities: 0.60032 (supplier 1), 0.03553 (supplier 2), 0.08584 (supplier 3), 0.15877 (supplier 4) and 0.11954 (supplier 5).

Table 5. Pair-wise comparison matrix of suppliers in relation to the SU1 criterion

\begin{tabular}{|c|c|c|c|c|c|c|}
\hline & Supplier 1 & Supplier 2 & Supplier 3 & Supplier 4 & Supplier 5 & Priorities \\
\hline Supplier 1 & 1 & 9 & 7 & 5 & 7 & 0.60032 \\
\hline Supplier 2 & $1 / 9$ & 1 & $1 / 3$ & $1 / 5$ & $1 / 5$ & 0.03553 \\
\hline Supplier 3 & $1 / 7$ & 3 & 1 & $1 / 3$ & 1 & 0.08584 \\
\hline Supplier 4 & $1 / 5$ & 5 & 3 & 1 & 1 & 0.15877 \\
\hline \multirow[t]{2}{*}{ Supplier 5} & $1 / 7$ & 5 & 1 & 1 & 1 & 0.11954 \\
\hline & & & & & $C R$ & 0.05575 \\
\hline
\end{tabular}


After obtaining all the pair-wise comparison matrices, the unweighted supermatrix was built (Superdecisions 2018). The supermatrix is an $n \times n$ matrix, where $n$ is each element of the model. The priorities that derive from the pair-wise comparisons are included in the unweighted supermatrix. Table 6 shows the unweighted supermatrix. As an example, the priorities of the business criteria in relation to the FO2 objective (obtained in Table 4) are introduced into Table 6 and depicted in italics.

In phase 5 , the final priorities were obtained. Table 7 shows the final priorities for all the elements: objectives, criteria and alternatives. For the alternatives (suppliers), Fig. 4 shows the normalised value of the final priorities. The final priorities can be read in the Normals column: 0.281924 (supplier 1), 0.204634 (supplier 2), 0.120398 (supplier 3), 0.269790 (supplier 4) and 0.123254 (supplier 5). After considering the results, supplier 1 took the highest priority and should be selected. In the final ranking, supplier 4 came second, supplier 2 third, supplier 5 fourth and supplier 5 last.

\begin{tabular}{|c|c|c|c|c|}
\hline Name & Graphic & Ideals & Normals & Raw \\
\hline Supplier 1 & & 1.000000 & 0.281924 & 0.093975 \\
\hline Supplier 2 & & 0.725849 & 0.204634 & 0.068211 \\
\hline Supplier 3 & & 0.427059 & 0.120398 & 0.040133 \\
\hline Supplier 4 & & 0.956961 & 0.269790 & 0.089930 \\
\hline Supplier 5 & & 0.437190 & 0.123254 & 0.041085 \\
\hline
\end{tabular}

Fig. 4. The final priorities for suppliers in Superdecisions ${ }^{\mathrm{TM}}$

Regarding objectives, Table 8 shows the normalised priorities, ordered from the highest to the lowest value. As observed in the normalised and accumulated columns, the three most important objectives of the BSC for supply chain sustainability are: FO2 (increase profitability), $\mathrm{CO} 1$ (increase customer satisfaction) and $\mathrm{IO} 1$ (increase innovation). They are assigned around 53.68 per cent of priority (accumulated value). In addition, there are other important objectives, such as $\mathrm{PO} 3$ (increase product safety), FO1 (reduce production costs), SO2 (increase $\mathrm{H} \& S$ culture) and $\mathrm{CO} 2$ (increase market share). The top three objectives and these four represent around 80 per cent of priority. Thus, they will be the most relevant to monitor in the supply chain.

Table 8. Priorities for the BSC objectives

\begin{tabular}{|l|c|c|}
\hline BSC Objectives & $\begin{array}{c}\text { Normalised and } \\
\text { ordered }\end{array}$ & Norm. Accumulated \\
\hline FO2 Increase profitability & 0.297951 & 0.297951 \\
\hline CO1 Increase customer satisfaction & 0.119421 & 0.417372 \\
\hline IO1 Increase innovation & 0.119421 & 0.536794 \\
\hline PO3 Increase product safety & 0.095535 & 0.632329 \\
\hline FO1 Reduce production costs & 0.070653 & 0.702982 \\
\hline SO2 Increase H\&S culture & 0.056331 & 0.759313 \\
\hline CO2 Increase market share & 0.039807 & 0.799120 \\
\hline IO2 Increase personnel's commitment & 0.039807 & 0.838927 \\
\hline
\end{tabular}




\begin{tabular}{|l|l|l|}
\hline EO1 Reduce environmental impact & 0.038013 & 0.876940 \\
\hline PO1 Increase shelf life & 0.031845 & 0.908785 \\
\hline PO2 Increase taste properties & 0.031845 & 0.940630 \\
\hline FO3 Reduce delivery cost & 0.027921 & 0.968551 \\
\hline SO1 Improve employment practices & 0.018777 & 0.987328 \\
\hline EO2 Increase pollution prevention & 0.012672 & 1.000000 \\
\hline
\end{tabular}

Finally, in phase 6 , a sensitivity analysis was performed to verify that the solution is consistent when modifying priorities. Fig. 5 shows the sensitivity analysis (plot mode) of the alternatives when modifying the priorities of objective FO2 (increase profitability). As observed, supplier 1 remains the preferred solution for all the values. When performing the same analysis (in the bar chart mode) for $\mathrm{CO} 1$ (increase customer satisfaction) (Fig. 6), the priority of this objective needs to increase to 0.684 to modify the solution (supplier 4 is thus the first option), which is quite a significant change. The solution proved consistent after performing the sensitivity analysis for the model.

Additionally, readers are referred to the following url to access Tables 6 and 7: http://www.cigip.upv.es/docs/2020_CEJOR_Verdecho\%20et\%20al_Publish.pdf

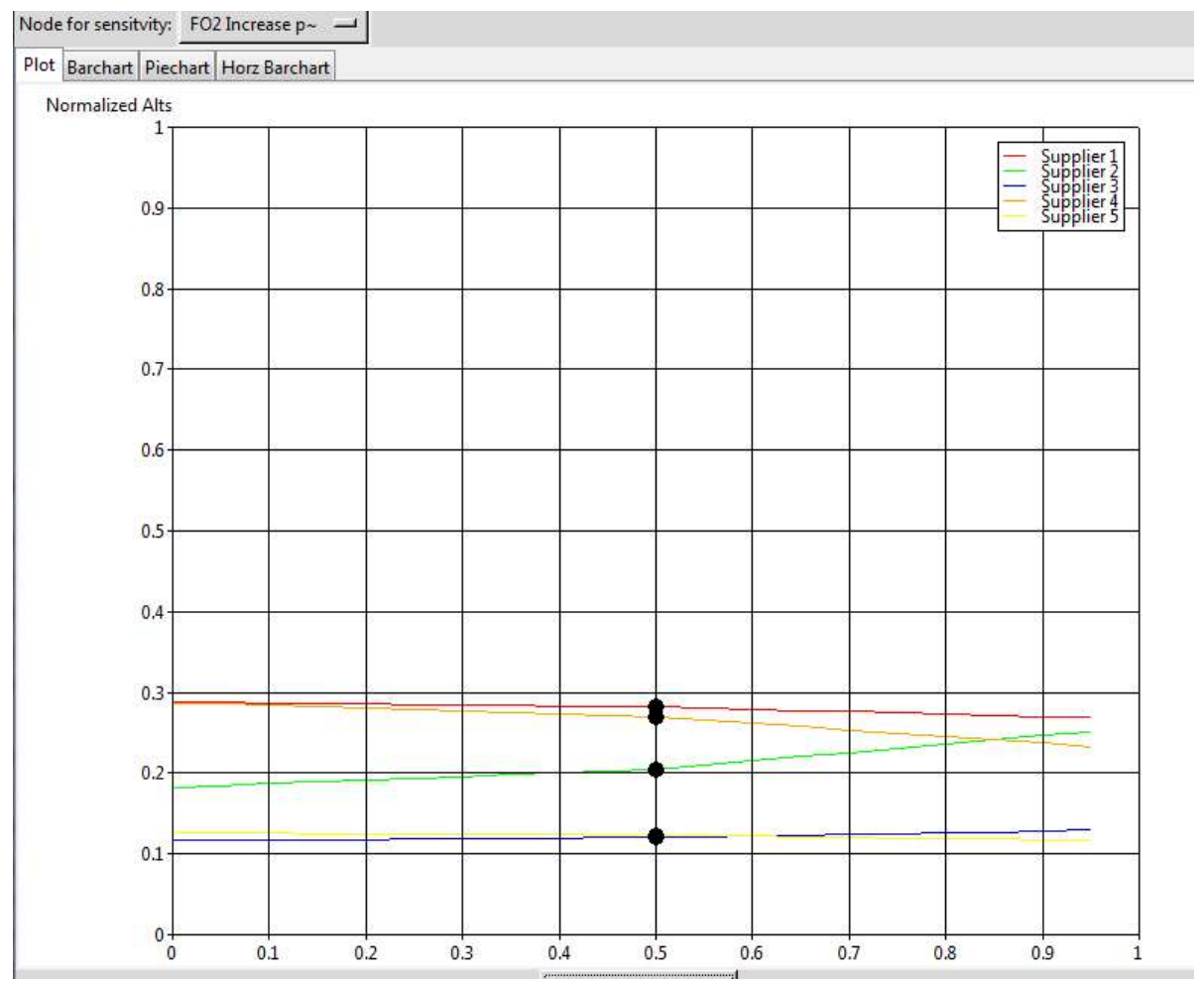

Fig. 5. Sensitivity analysis for alternatives as regards objective FO2 in Superdecisions ${ }^{\mathrm{TM}}$ 


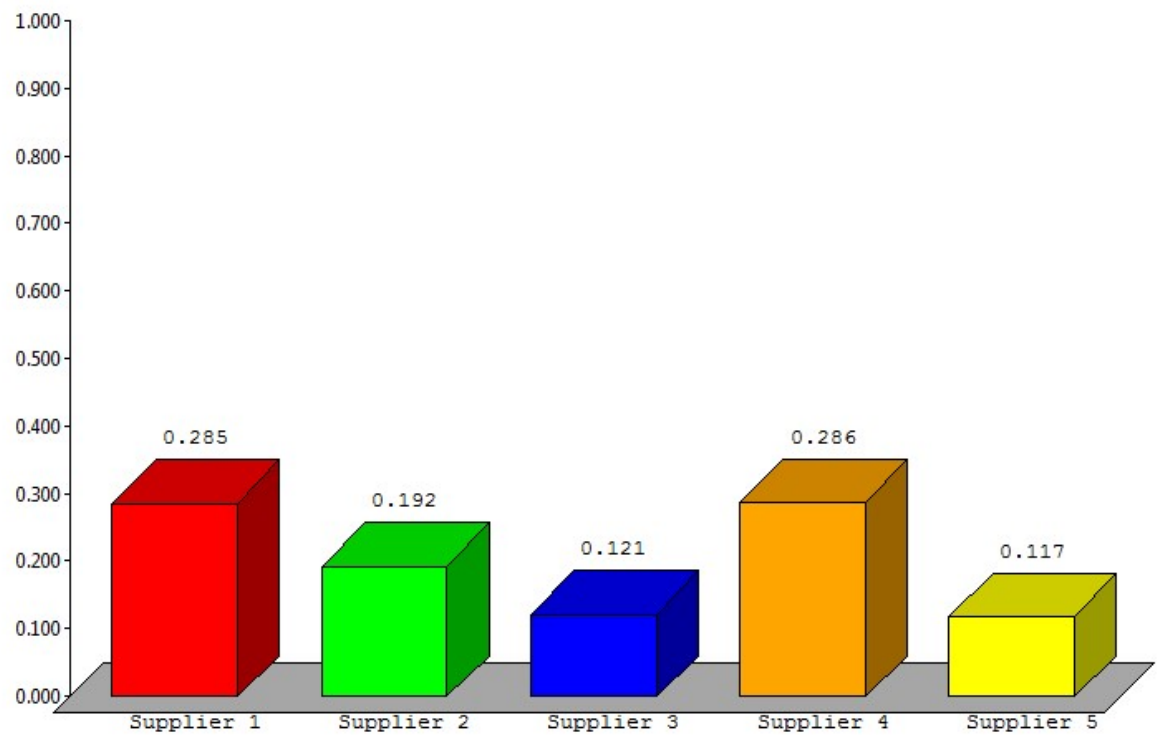

Fig. 6. Sensitivity analysis for alternatives regarding objective CO1 in Superdecisions ${ }^{\mathrm{TM}}$

\section{Conclusions}

The literature offers different tools and models to select suppliers, but lacks a proper model to integrate the supplier selection process with supply chain sustainability management to increase synergies toward sustainability and, at the same time, obtain coherence between the supplier selection process and the supply chain's deployed strategy. This paper develops an MCDA methodology that focuses on bridging this gap by establishing two main groups of criteria to select suppliers: the supply chain's sustainability performance and sustainable supplier selection criteria. Applying this methodology provides many benefits. The first is to support the definition of the supply chain strategy. The second focuses on a strategy for longterm sustainability. The third clarifies and understands the main criteria to select suppliers by considering the supply chain's sustainability. Finally, the last is about using the AHP to structure and compute the decision problem, because it allows decision-makers' judgements to be introduced. The methodology has been applied to an agri-food supply chain, and ranked five suppliers. Future research shall focus on validating this methodology in other applications (other supply chains) and on introducing uncertainty (such as fuzzy sets) into MCDA models to compare the obtained results.

\section{Acknowledgements}

The authors of this publication acknowledge the contribution of Project GV/2017/065 'Development of a decision support tool for the management and improvement of sustainability in supply chains', funded by the Regional Valencian Government. Also, the authors acknowledge Project 691249, RUC-APS: Enhancing and implementing knowledgebased ICT solutions within high risk and uncertain conditions for agriculture production 
systems (www.ruc-aps.eu), funded by the European Union according to funding scheme H2020-MSCA-RISE-2015.

\section{References}

Agarwal G, Vijayvargy L (2012) Green supplier assessment in environmentally responsive supply chains through analytical network process. In: Proceedings international multiconference of engineers and computer scientists, Hong Kong

Ageron B, Gunasekaran A, Spalanzani A (2012) Sustainable supply management: an empirical study. Int J Prod Econ 140(1):168-182

Akarte MM, Surendra NV, Ravi B, Rangaraj N (2001) Web based casting supplier evaluation using analytical hierarchy process. J Oper Res Soc 52:511-522

Alfaro JJ, Ortiz A, Rodríguez R (2007) Performance measurement system for enterprise networks. Int J Productivity Perform Manag 56(4):305-334

Alfaro Saiz JJ, Rodríguez R, Ortiz Bas A, Verdecho MJ (2010) An information architecture for a performance management framework by collaborating SMEs. Computers in Industry 61:676685

Awasthi A, Govindan K, Gold S (2018) Multi-tier sustainable global supplier selection using a fuzzy AHP-VIKOR based approach. Int J Prod Econ 195:106-117

Azadnia AH, Ghadimi P, Zameri M, Saman M, Wong KY, Heavey C (2013) An integrated approach for sustainable supplier selection using fuzzy logic and fuzzy AHP. Appl Mechanics and Materials 315:206-21

Azimifard A, Moosavirad SH, Ariafar S (2018) Selecting sustainable supplier countries for Iran's steel industry at three levels by using AHP and TOPSIS methods. Resour Pol 57:30-44

Bai C, Sarkis J (2010) Integrating sustainability into supplier selection with grey system and rough set methodologies. Int J Prod Econ 124: 252-264

Bhagwat R, Sharma MK (2007) Performance measurement of supply chain management: a balanced scorecard approach. Computers and Industrial Engineering 53(1):43-62

Bititci US, Mendibil K, Martinez V, Albores P (2005) Measuring and managing performance in extended enterprises. Int J Operations \& Production Management 25(4):333-353

Brewer PC, Speh TW (2000) Using the balanced scorecard to measure supply chain performance. J Bus Logist 21(1):75-93

Bullinger HJ, Kühner M, Hoof AV (2002) Analysing supply chain performance using a balanced measurement method Int. J of Prod Res 40(15):3533-3543

Chan FTS (2003) Interactive selection model for supplier selection process: an analytical hierarchy process approach. Int J Prod Res 41(15):3549-3579

De Boer L, Labro E, Morlacchi P (2001) A review of methods supporting supplier selection. European Journal of Purchasing and Supply Management 7(2):75-89

Degraeve Z, Labro E, Roodhooft F (2000) An evaluation of supplier selection methods from a total cost of ownership perspective. European J of Operational Research 125(1):34-58 
Dobos I, Vörösmarty G (2014) Green supplier selection and evaluation using DEA-type composite indicators. Int J of Prod Econ 157(11):273-278

Dou Y, Sarkis J (2010) A joint location and outsourcing sustainability analysis for a strategic offshoring decision. Int J Prod Res 48(2):567-592

Dyllick T, Hockerts K (2002) Beyond the business case for corporate sustainability. Bus Strategy Environ 11:130-141

Falatoonitoosi E, Leman Z, Sorooshian S (2013) Modeling for green supply chain evaluation. Math Probl Eng 2013, 1-9

Farzad T, Rasid OM, Aidy A, Rosnah MY, Alireza E (2008) AHP approach for supplier evaluation and selection in a steel manufacturing company. JIEM 1(2):54-76

Ferreira LMDF, Silva C, Garrido Azevedo S (2016) An environmental balanced scorecard for supply chain performance measurement (Env_BSC_4_SCPM). Benchmarking: An International Journal 23(6):1398-1422

Figge F, Hahn T, Schaltegger S, Wagner M (2002) The sustainability balanced scorecard: linking sustainability management to business strategy. Bus Strat Env 11:269-284

Folan P, Browne J (2005) Development of an extended enterprise performance measurement system. Prod Plan and Control 16(6):531-544

Freeman J, Chen T (2015) Green supplier selection using an AHP-entropy-TOPSIS framework. Supply Chain Manag 20:327-340

Genovese A, Koh L, Bruno G, Esposito E (2013) Greener supplier selection: state of the art and some empirical evidence. Int J Prod Res 51(10):2868-2886

Ghodsypour SH, O'Brien C (1998) A decision support system for supplier selection using an integrated analytic hierarchy process and linear programming. Int J Prod Econ 56-57:199-212

Glock CH, Grosse EH, Ries JM (2017) Decision support models for supplier development: systematic literature review and research agenda. Int J Prod Econ 194:246-260

Govindan K, Khodaverdi R, Jafarian A (2013) A fuzzy multi criteria approach for measuring sustainability performance of a supplier based on triple bottom line approach. J Clean Prod 47:345-354

Govindan K, Rajendran S, Sarkis J, Murugesan P (2015) Multi criteria decision making approaches for green supplier evaluation and selection: a literature review. J Clean Prod 98:66-83

Gunasekaran A, Patel C, Tirtiroglu E (2001) Performance measures and metrics in a supply chain environment. International Journal of Operations and Production Management 21(1/2):71-87

Ho W, Xu X, Dey PK (2010) Multi-criteria decision making approaches for supplier evaluation and selection: a literature review. European J of Operational Research 202:16-24

Hsu CW, Hu AH (2009) Applying hazardous substance management to supplier selection using analytic network process. J Clean Prod 17(2):255-264 
Hsu CW, Kuo TC, Chen SH, Hu AH (2013) Using DEMATEL to develop a carbon management model of supplier selection in green supply chain management. J Clean Prod 56:164-172

Huan SH, Sheoran SK, Wang G (2004) A review and analysis of supply chain operations reference (SCOR) model. Supply Chain Management: An International Journal 9(9):23-29

Hutchins M, Sutherland JH (2008) An exploration of measures of social sustainability and their application to supply chain decisions. J Clean Prod 16(15):1688-1698

Igarashi M, Boer L, Magerholm Fet A (2013) What is required for greener supplier selection? A literature review and conceptual model development. Journal of Purchasing and Supply Management 19(4):247-263

Jimenez-Jimenez D, Martínez-Costa M, Sanchez Rodriguez C (2019) The mediating role of supply chain collaboration on the relationship between information technology and innovation. Journal of Knowledge Management 23(3):548-567

Kaplan RS, Norton DP (1992) The balanced scorecard: measures that drive performance. Harvard Business Review 70(1):71-79

Luthra S, Govindan K, Kannan D, Kumar Mangla S, Prakash Garg C (2017) An integrated framework for sustainable supplier selection and evaluation in supply chains. J Clean Prod 140:1686-1698

Maestrini V, Luzzini D, Maccarrone P, Caniato F (2017) Supply chain performance measurement systems: a systematic review and research agenda. Int J Prod Econ 183A:299315

Masella C, Rangone A (2000) A contingent approach to the design of vendor selection systems for different types of co-operative customer/supplier relationships. International Journal of Operations \& Production Management 20(1):70-84

Miller GA (1956) The magical number seven, plus or minus two: some limits on our capacity for processing information. Psychological Review 63:81-97

Mohammed A, Harris I, Govindan K (2019) A hybrid MCDM-FMOO approach for sustainable supplier selection and order allocation. Int J Prod Econ 217: 171-184

Motevali-Haghighi S, Torabi SA, Ghasemi R (2016) An integrated approach for performance evaluation in sustainable supply chain networks (with a case study). J Clean Prod 137:579-597

Nawaz W, Koç M (2018) Development of a systematic framework for sustainability management of organizations. J Clean Prod 171:1255-1274

Nie X (2013) Green suppliers selecting based on analytic hierarchy process for biotechnology industry. In: Zhong $Z$ (ed) Proceedings of the International Conference on Information Engineering and Applications. Springer, London, pp 253-260

Nielsen IE, Banaeian N, Golińska P, Mobli H, Omid M (2014) Green supplier selection criteria: from a literature review to a flexible framework for determination of suitable criteria. In: Golinska P (ed) Logistics operations, supply chain management and sustainability. Springer, Cham, pp 79-99 
Noci G (1997) Designing 'green' vendor rating systems for the assessment of a supplier's environmental performance. European Journal of Purchasing \& Supply Management 3(2):103114

Petersen KJ, Handfield RB, Ragatz GL (2005) Supplier integration into new product development: coordinating product, process and supply chain design. Journal of Operations Management 23:371-388

Pishchulov G, Trautrims A, Chesney T, Gold S, Schwab L (2019) The voting analytic hierarchy process revisited: a revised method with application to sustainable supplier selection. Int $\mathrm{J}$ Prod Econ 211:166-179

Popovic, T, Kraslawski, A, Barbosa-Póvoa A, Carvalho A (2017) Quantitative indicators for social sustainability assessment of society and product responsibility aspects in supply chains. J Int Stud 10(4):9-36

Qorri A, Mujki Z, Kraslawski A (2018) A conceptual framework for measuring sustainability performance of supply chains. J Clean Prod 189:570-584

Reefke H, Trocchi M (2013) Balanced scorecard for sustainable supply chains: design and development guidelines. International Journal of Productivity and Performance Management 62(8):805-826

Saaty RW (1987) The analytic hierarchy process: what it is and how it is used. Mathematical Modelling 9(3-5):161-176

Saaty TL (1980) The analytic hierarchy process. McGraw-Hill, New York

Saaty TL (2008) Decision making with the analytic hierarchy process. Int J Services Sciences $1(1): 83-98$

Saaty TL, Ozdemir MS (2003) Why the magic number seven plus or minus two. Mathematical and Computer Modelling 38(3-4):233-244

Seuring S, Müller M (2008) From a literature review to a conceptual framework for sustainable supply chain management. J Clean Prod 16:1699-1710

Shaik M, Abdul-Kader W (2011) Green supplier selection generic framework: a multi-attribute utility theory approach. International Journal of Sustainable Engineering 4(1):37-56

Shi P, Yan B, Shi S, Ke C (2015) A decision support system to select suppliers for a sustainable supply chain based on a systematic DEA approach. Information Technology and Management 16(1):39-49

Superdecisions (2018) Tutorial on hierarchical decision models. Creative Decisions Foundation. https://www.superdecisions.com/sd_resources/v28_man03.pdf. Accessed 7 January 2018

Thakkar J, Kanda A, Deshmukh S (2009) Supply chain performance measurement framework for small and medium scale enterprises, Benchmarking: An International Journal 16(5):702723

Theißen S, Spinler S (2014) Strategic analysis of manufacturer-supplier partnerships: an ANP model for collaborative $\mathrm{CO} 2$ reduction management. European Journal of Operational Research 233(2):383-397 
Tseng ML, Lim M, Wong WP (2015) Sustainable supply chain management: a closed-loop network hierarchical approach. Industrial Management \& Data Systems 115(3):436-461

Uysal F (2012) An integrated model for sustainable performance measurement in supply chain. Procedia-Social and Behavioral Sciences 62:689-694

Valenzuela L, Maturana S (2016) Designing a three-dimensional performance measurement system (SMD3D) for the wine industry: a Chilean example. Agricultural Systems 142:112-121

Verdecho MJ, Alfaro-Saiz JJ, Rodriguez-Rodriguez R, Ortiz-Bas A (2012) A multi-criteria approach for managing inter-enterprise collaborative relationships. Omega 40:249-263

Virender P, Jayant A (2014) A green supplier selection model for an agriculture-machinery industry. International Journal of Applied Engineering Research 9(5):597-605

Weber CA, Current JR, Benton WC (1991) Vendor selection criteria and methods. European J of Operational Research 50(1):2-18

Xu L, Kumar DT, Madan Shankar K, Kannan D, Chen G (2013) Analyzing criteria and sub-criteria for the corporate social responsibility-based supplier selection process using AHP. The International Journal of Advanced Manufacturing Technology 68(1-4):907-916

Xu Z, Qin J, Liu J, Martínez L (2019) Sustainable supplier selection based on AHP Sort II in interval type-2 fuzzy environment. Information Sciences 483:273-293

Zaklad A, McKnight R, Kosansky A, Piermarini J (2004) The social side of the supply chain. Industrial Engineer 36(2):40-44

Zhe S, Wong NT, Lee LH (2013) Using data envelopment analysis for supplier evaluation with environmental considerations. In: International Systems Conference, Orlando

Zimmer K, Fröhling M, Schultmann F (2016) Sustainable supplier management: a review of models supporting sustainable supplier selection, monitoring and development. Int J Prod Res 54(5):1412-1442 